\title{
Identidades compartidas: la centralidad de los lazos culturales como motor paradiplomático*
}

\author{
Victorino Morales DÁviLA** \\ Carlos Manuel Reyes Silva**
}

Artículo recibido: 21 de abril de 2015

Artículo aprobado: 25 de agosto de 2015

Doi: dx.doi.org/10.12804/desafios28.1.2016.02

Para citar este artículo: Morales Dávila, V. \& Reyes Silva, C. M., (2016). Identidades compartidas: la centralidad de los lazos culturales como motor paradiplomático. Desafíos, 28(I), 79-120. Doi: dx.doi.org/10.12804/desafios28.1.2016.02

\section{Resumen}

Elpresente articulo tiene por objetivo analizar la incidencia del factor identitario en las actividades paradiplomáticas. Para ello, se ha desarrollado un marco de pensamiento a partir de la adaptación de ciertas teorías de las Relaciones Internacionales al campo de la paradiplomacia. Asimismo, se introduce una propuesta metodológica por medio de categorías analíticas, la cual ha sido aplicada a tres casos de estudio que, debido

\footnotetext{
* El presente artículo de investigación científica surge de las temáticas abordadas en las tesis de ambos autores, así como en el marco de investigaciones que se producen en el grupo Asuntos Globales, del Tecnológico de Monterrey.

** Doctorando en Ciencias Sociales por el Tecnológico de Monterrey, Campus Monterrey, México. Adscrito a la línea de investigación Asuntos Globales del mismo programa doctoral. Licenciado en Relaciones Internacionales, Tecnológico de Monterrey, Campus Monterrey, Nuevo León, México. Correo electrónico: victorino04@gmail.com

*** Doctorando en Ciencias Sociales por el Tecnológico de Monterrey, Campus Monterrey, México. Adscrito a la línea de investigación Asuntos Globales del mismo programa doctoral. Licenciado en Relaciones Comerciales Internacionales, Universidad Latina de América, Michoacán, México. Correo electrónico: lrcisilva@yahoo.com
} 
a sus particularidades, sirven para ilustrar este fenómeno: la relación de Quebec con Francia, las colectividades vascas francesas con respecto al País Vasco y Navarra, y el Gobierno Regional de Kurdistán en relación con las localidades kurdas de los Estados vecinos a Iraq. Así, el análisis teórico-empirico ayudará a entender de qué modo la elección del actor con el que se pretende colaborar parte de una identificación reciproca, esto es que se sienten parte de una misma colectividad. Lo anterior no sólo puede motivar la relación paradiplomática sino que incluso puede ser una finalidad, la cual se traduce en acuerdos de preservación respecto a la cultura compartida por ambas partes. Sin embargo, las peculiaridades de cada caso evidenciarán que, aunque la identidad sirva como motor paradiplomático, existen otros factores que reducen su potencial de cooperación.

Palabras clave: Paradiplomacia, identidad, gobiernos subnacionales, cooperación.

\title{
Shared Identities: The Centrality of Cultural Bonds as a Paradiplomatic Engine
}

\begin{abstract}
This article aims to analyze the relevance of identity factors in paradiplomatic activities. To this end, we have developed a framework adapting certain theories from International Relations to the field of Paradiplomacy. In addition, a methodology based on analytical categories is introduced and applied to three case studies which due to their particularities serve to illustrate this phenomenon: the relationship between Quebec and France, the French Basque communities with respect to the Basque Country and Navarre, and the Kurdistan Regional Government in relation to the Kurdish towns in the neighbor states of Iraq. The theoretical and empirical analysis helps to understand the choice of an actor to cooperate as part of a mutual identification, meaning that they feel part of a bigger community. This may not only motivate the paradiplomatic relationship but it might even be an end in itself, as it may lead to agreements regarding the preservation of the culture shared by both parties. However, the peculiarities of each case show that, although identity serves as a paradiplomatic engine, there are other factors that reduce the potential for cooperation.
\end{abstract}

Keywords: Paradiplomacy, identity, subnational governments, cooperation. 


\title{
Identidades compartilhadas: a centralidade dos laços culturais como motor paradiplomático
}

\begin{abstract}
Resumo
O presente artigo tem por objetivo analisar a incidência do fator identitário nas atividades paradiplomáticas. Para isso, se tem desenvolvido um marco de pensamento a partir da adaptação de certas teorias das Relações Internacionais ao campo da paradiplomacia. Igualmente, introdur-se uma proposta metodológica por meio de categorias analiticas, a qual tem sido aplicada a três casos de estudo que, devido a suas particularidades, servem para ilustrar este fenômeno: a relação do Quebec com a França, as coletividades vascas francesas com respeito ao País Vasco e Navarra, e o Governo Regional do Curdistão em relação com as localidades curdas dos Estados vizinhos ao Iraq.

Assim, a análise teórico-empírica ajudará a entender de que modo a eleição do ator com o que se pretende colaborar parte de uma identificação recíproca, isto é que se sentem parte de uma mesma coletividade. O anterior não só pode motivar a relação paradiplomática senão que inclusive pode ser una finalidade, a qual se traduz em acordos de preservação respeito à cultura compartilhada por ambas as partes. No entanto, as peculiaridades de cada caso evidenciarão que, ainda que a identidade sirva como motor paradiplomático, existem outros fatores que reduzem seu potencial de cooperação.
\end{abstract}

Palavras -chave: Paradiplomacia, identidade, governos subnacionais, cooperação.

\section{Introducción}

Los estudios de paradiplomacia se han limitado a observar el fenómeno desde una perspectiva que privilegia el estudio de los factores racionalistas y utilitaristas. Así, es común observar en estos análisis que la paradiplomacia obedece a cuestiones como el impulso al desarrollo de la localidad, el incremento de prestigio a nivel internacional, la profundización de vínculos comerciales, la recepción de ayuda, el involucramiento de otros actores para mejorar las condiciones de vida de la región, etcétera. Sin embargo, existen otros factores capaces de motivar las actividades paradiplomáticas, entre los cuales se encuentra la identidad. 
$\mathrm{Al}$ respecto, la hipótesis de esta investigación parte de la importancia de pertenecer a una identidad colectiva o, al menos, de compartir varios referentes identitarios, como un impulso de determinados gobiernos subnacionales en la búsqueda por desarrollar sus relaciones con otros actores del sistema internacional. Incluso, la misma preservación de ciertos referentes puede ser una finalidad en sí misma de este tipo de acciones y acuerdos. Por lo tanto, para poder observar la incidencia que tiene la identidad en las actividades paradiplomáticas, en un primer momento se llevará a cabo una reflexión tanto de los fines como de las motivaciones que son abarcadas por las actividades paradiplomáticas; dicho análisis servirá para observar los tipos de estudios que se han realizado y el papel limitado que se le ha dado a la identidad dentro de este proceso.

Posteriormente, se desarrollará un marco teórico que tome como punto de partida los aportes de la corriente constructivista de las Relaciones Internacionales, adaptándolos al contexto de la esfera paradiplomática y agregándoles ciertas especificaciones. Enseguida, se presentarán las categorías analíticas que permitan estudiar tres casos de estudio, los cuales, debido a sus particularidades, permiten ilustrar el fenómeno de la paradiplomacia identitaria: el gobierno de Quebec con el Estado francés, las colectividades vascas francesas con respecto a los provincias vascas de España -País Vasco y Navarra-, y el Kurdistán iraquí en relación a las poblaciones kurdas de los Estados de Siria, Turquía e Irán. Después de la descripción de cada caso, se presentarán los resultados mediante la aplicación de las categorías de análisis y con ello poder contar con una mejor lectura que evidencie las similitudes y diferencias entre estos tres procesos, para así arribar a las conclusiones.

Antes de comenzar, se debe señalar que la selección de estos casos ha respondido a una preocupación por el enfoque con el que han sido previamente estudiados. Por un lado, el estudio de las relaciones de Quebec con Francia es mucho menor que los análisis en torno a sus intentos separatistas o al despliegue indiferenciado de sus relaciones autónomas con el exterior. Por su parte, en el caso de los vascos se ha privilegiado el análisis paradiplomático de Euskadi en relación a 
su autonomía, considerando que dicha actividad es producto de su identidad en tanto diferenciación con respecto a España, sin atender el modo en que ésta genera cierto tipo de lazos. Aparte, mucho menos se ha observado este fenómeno desde el lado de las colectividades vascas en Francia, por lo que, en esta ocasión, ambas consideraciones se han tenido presentes. Del otro lado, el caso de los kurdos iraquíes se estudia generalmente con respecto a los gobiernos vecinos, mitigando el papel de las poblaciones kurdas que se localizan en dichos Estados, cuestión que también se ha intentado revertir en este artículo. Por último, cabe mencionar que este ensayo no sólo pretende renovar el debate sobre el factor identitario dentro del campo de las Relaciones Internacionales, sino que aspira a impulsar el análisis de esta relación y de dichos casos de estudio entre los académicos latinoamericanos, debido a las potencialidades que tiene para la región. ${ }^{1}$

\section{La paradiplomacia: un campo de múltiples finalidades y perspectivas}

La actividad internacional de los gobiernos subnacionales es un fenómeno que se ha intensificado a lo largo del siglo XX. Por ejemplo, el inicio de la participación de los gobiernos subnacionales en la cooperación internacional puede ubicarse a principios del siglo pasado, con la creación de la Unión Internacional de Autoridades Locales, la cual pudo consolidarse eventualmente a la par que otras asociaciones en la organización de Ciudades y Gobiernos Locales Unidos (Ponce, 2011). Sin embargo, aunque la presencia exterior de los gobiernos subnacionales no es reciente, la preocupación por su estudio como categoría

\footnotetext{
1 La vinculación de la identidad con la paradiplomacia en América Latina coadyuvaría a los estudios de indigenismo en las Relaciones Internacionales. Asimismo, su aplicación serviría para profundizar la explicación en su modelo tradicional, que involucra a un gobierno subnacional, como el caso del estado mexicano de Chiapas respecto a Guatemala o aquél de la provincia argentina de Corrientes en relación a Paraguay, con quien comparten no sólo una trayectoria histórica, sino también la lengua guaraní. Por su parte, sus aportes dentro de marcos más particulares -donde la entidad de origen no es necesariamente un gobierno subnacional- también serían interesantes, tal como ocurre con el caso de las comunidades binacionales de los kikapú en el noreste de México y sur de Estados Unidos, la comunidad chiquitana que reside en Brasil o incluso en los mismos Congresos Mundiales de Quechua.
} 
analítica comienza algunas décadas atrás; es por ello que Zeraoui ha señalado que la paradiplomacia es "una nueva tendencia donde los subgobiernos $[\ldots]$ toman acciones autónomas en cuestión de relaciones internacionales" (2013, p. 24).

La conceptualización de los gobiernos subnacionales como actores del sistema internacional y como unidades de análisis en las Relaciones Internacionales comienza en la década de los setenta, cuando un pluralismo teórico y metodológico presentaba un reto al paradigma realista o neorrealista. Desde las aproximaciones teóricas neoliberales y de la economía política internacional empieza a desafiarse el carácter estrictamente militar, jurídico-legalista y de poder con el que el realismo estatocentrista caracterizaba a los actores. De este modo, el nuevo paradigma abría las puertas a considerar a las entidades subestatales como actores del sistema internacional, resaltando su dinamismo, movilización y capacidad para concretar objetivos y ejercer influencia sobre otros actores del sistema.

La novedosa formulación transnacionalista y de interdependencia compleja propuesta por Keohane \& Nye (1987), apartó la lucha de poder para concentrarse en las negociaciones que surgen entre una variedad de actores autónomos y semiautónomos. Esta consideración supuso que no sólo los Estados nacionales pueden movilizarse e influir en el sistema internacional, ya que si la maximización del poder en términos políticos y militares ha dejado de ser el objetivo central de los estudios de la política internacional, otras entidades pueden interactuar globalmente con significaciones importantes para la política mundial. Lo anterior trajo como consecuencia el surgimiento de estudios abocados al estudio de la acción exterior de los gobiernos subnacionales, dentro de los cuales las primeras obras fueron realizadas por Ivo Duchacek \& Panayotis Soldatos a finales del siglo XX; de hecho, el primero utilizaría el concepto paradiplomacia para definir "las entradas directas o indirectas de los gobiernos no centrales al campo de las relaciones internacionales" (1990, p. 15), empleando así el prefijo para como "paralelo" o "asociado" respecto al gobierno central. 
Esta conceptualización de la actividad exterior que desarrollan los gobiernos subnacionales puede entenderse tanto en términos de la extensión de poder de los mismos y de las situaciones domésticas relacionadas a la división territorial, así como parte de una transformación del orden internacional. Además, es posible afirmar que las relaciones que surgieron de estas actividades han trascendido la naturaleza gubernamental de los actores, permitiendo así la vinculación entre comunidades, partidos, colectivos y otros agentes ${ }^{2}$ que, desde perspectivas menos rígidas, constituyen entidades subestatales. Bajo esta lógica, la acción exterior subestatal puede ser definida como la capacidad de agencia internacional que puede desarrollar dicha entidad, misma que de acuerdo con Lecours (2002), no debe pensarse como un aspecto de jure. En este sentido, la estructura misma de la política internacional es la que provoca la rutinización de la acción exterior, de la cual procuran tomar beneficio las entidades subestatales. De nueva cuenta, las mismas dinámicas domésticas se relacionan con los cambios estructurales a nivel global, proyectando a todas aquellas entidades subestatales en la política global; esto es el juego definido como glocalización, el cual tiene en consideración este tipo de oportunidades estructurales a nivel global (Keating, 1997).

Debido a que el interés de esta investigación se basa en el desarrollo de la paradiplomacia identitaria, conviene pasar directamente a los abordajes y perspectivas sobre los que se ha estudiado este tema, con el objetivo de ubicar la presente propuesta dentro del estado de la cuestión. La proliferación de estos análisis teórico-empíricos tan distintos, a pesar de su reciente uso en espacios académicos como el latinoamericano, ha obedecido a varios factores que originan dos vertientes de estudios, las cuales pueden o no estar directamente relacionadas: de acuerdo a la finalidad de la actividad paradiplomática

\footnotetext{
2 A pesar de que los términos 'actor' y 'agente' poseen connotaciones distintas -aunque no universalmente consensuadas-, a lo largo de este trabajo se hará un uso indistinto entre ambos conceptos. Ello obedece no sólo al uso tan arbitrario que muchas veces se encuentra entre ambos, sino a que no es necesario contraponer los objetivos del artículo con la estructura, ni demostrar el grado de volición o voluntarismo. Encima, al trabajar con entidades de variada naturaleza como los gobiernos subnacionales, Estados-nación o comunidades, su uso descriptivo en tanto actores o agentes colectivos es el mismo.
} 
y en relación al encuadre dentro de una determinada corriente de pensamiento. Dentro de la primera, Aldecoa (1999) señala que existen tres principales finalidades que generan la actividad paradiplomática: las económicas, las políticas y las culturales. Así, mientras en el primer grupo el motor radica en la captación de capital extranjero, el desarrollo local y la profundización de los vínculos comerciales, el segundo grupo hace referencia al aumento de prestigio a nivel internacional o a la solución de conflictos. Por su parte, dentro del tercer grupo se hallarían el estrechamiento de los lazos culturales, la preservación de una cultura o el fomento de intercambios y demás actividades que se enmarcan dentro de la paradiplomacia identitaria. ${ }^{3}$

Respecto a las corrientes de pensamiento, habrá algunas aproximaciones neorrealistas que traten de reducir la importancia del fenómeno paradiplomático respecto a la actividad de los Estados-nación (Cornago, 1999; John, 1996; Milward, 1992; Moracsik, 1993, 1998; Putman, 1998) o algunos más inclinados al neoliberalismo que se decanten por el énfasis en el desarrollo de las instituciones y la cooperación entre éstas (Balme, 1996; Keohane \& Nye, 1989). Asimismo, los estudios de corte racionalista enfatizarán el carácter utilitarista de la paradiplomacia, subrayando la búsqueda de un interés o beneficio -generalmente económico- propio, así como el fortalecimiento de su seguridad (Keating, 2000; Leonardy, 1992; Jeffery, 1996; Ohmae, 1997). Por su parte, los enfoques marxistas podrán poner dicho fenómeno bajo la óptica de las relaciones centro-periferia y el modo en que las condiciones de desigualdad inciden en esto (Winnie, 1997). Por último, quienes decidan partir de un marco constructivista (Badie, 1995; Le Galès \& Lequesne, 1997; Messart-Piérard,1997; Paquin, 2004; Peterson \& Bomberg, en 1999) estarán interesados por los factores 'menos racionalistas', tales como la identidad, la cultura, la historia y el proceso de interacción entre los agentes de la relación.

\footnotetext{
3 Las motivaciones anteriores impulsan el despliegue de estrategias tales como: el cabildeo, los hermanamientos, los acuerdos interinstitucionales, la creación de redes o alianzas, la apertura de oficinas de representación en otros países, así como el establecimiento de oficinas de asuntos internacionales dentro del gabinete, asociaciones nacionales, regionales o mundiales de autoridades locales (Velázquez 2006; Ortega Ramírez, 2012).
} 
La diferenciación anterior no intenta hacer un llamado a pensar la paradiplomacia desde ópticas excluyentes, ${ }^{4}$ sino que busca reflejar cómo, aun partiendo de la reciente producción teórica sobre este fenómeno, se ha podido llevar a cabo una diversidad de estudios al respecto. ${ }^{5}$ Asimismo, busca evidenciar de qué modo la paradiplomacia no se inserta únicamente en un marco racionalista de corte económico o político, ya que si bien las entidades subestatales realizan actividades que el gobierno central no es capaz de llevar a cabo, éstas no tienen que evocar necesariamente desarrollo, crecimiento, estabilidad, prestigio o seguridad.

Por último, lo anterior pretende mostrar la localización de este artículo dentro de la motivación cultural, partiendo de un enfoque constructivista. No obstante, busca diferenciarse de estudios similares que, aun partiendo del interés en la cultura y en la identidad, únicamente se han concentrado en señalar la diferenciación que se tiene con respecto a la identidad nacional del Estado donde se encuentran, lo cual les motiva a desarrollar una agenda propia. Bajo esta lógica tan limitada, diferenciación y paradiplomacia identitaria son homologadas, cuando en realidad debería de observarse la construcción de las relaciones que se realizan sobre la similitud de los lazos culturales con los agentes seleccionados de destino.

\footnotetext{
4 De hecho, una sola motivación por sí sola quizá no despliegue toda la actividad paradiplomática. Del mismo modo, los estudios tampoco deberían considerar las variables aisladas. En este sentido, el siguiente señalamiento es ilustrador: "la paradiplomacia generalmente refleja, o bien desigualdades económicas o bien crisis de identidad (y frecuentemente ambas) en función de que algunos grupos subnacionales dejan de sentirse representados por sus autoridades estatales" (Sarquís, 2013, p. 90).

5 Cabe mencionar que las aproximaciones académicas al fenómeno de la paradiplomacia han tenido un enfoque particularista, orientado a los estudios de caso. Aunque este tipo de estudios sea útil para ejemplificar, es menester desarrollar encuadres teórico-metodológicos que refuercen el aspecto interpretativo de este tipo de actividad exterior y su impacto en la configuración del sistema internacional.
} 


\section{Identidad y actividad internacional de las entidades subnacionales}

Antes de trasladarse al campo de las entidades subnacionales, es necesario recuperar la importancia de la identidad en las Relaciones Internacionales, ya que las variables ideacionales se han posicionado como uno de los grandes tópicos dentro de esta disciplina y en los estudios de política exterior. A este respecto, han sido los académicos propios del constructivismo y las teorías reflectivistas quienes mayormente han cuestionado la centralidad de los factores racionales, estructurales y materialistas que tanto habían influido en esta área para dar cabida a otro tipo de componentes. De este modo, dichos teóricos han procurado explicar cómo el comportamiento de los Estados también era definido en gran parte por lo ideacional, cubriendo así identidades (Bloom, 1993; Guillaume, 2011; Hopf, 2002), normas (Finnemore \& Sikkink, 1998; Katzenstein, 1996), significados compartidos (Kubálkova, 2001; Onuf 2013) y demás cuestiones culturales (Lapid \& Kratochwil, 1996; Subotic \& Zarakol, 2013), todos los cuales se han construido intersubjetivamente, ya sea a través de las relaciones e interacciones con otros actores (Mitzen, 2006; Steele, 2008; Wendt, 1999) o mediante los procesos históricos que ocurren dentro de los Estados (Berenskoetter, 2012; Bozdağlioğlu, 2003).

Si bien el bagaje teórico recién presentado ha sido aplicado — principalmente- sobre un paradigma estatocentrista, la introducción de otros niveles y agentes en las Relaciones Internacionales presenta una amplia gama de oportunidades, abriendo la posibilidad de extrapolar los aportes mencionados al estudio de las actividades internacionales que se desprenden de los gobiernos subnacionales. Sin embargo, es necesario detenerse y detallar cómo puede llevarse esto a cabo, debido a las particularidades que encierran los nuevos sujetos-objeto de estudio y las consecuencias que conlleva dicha adaptación.

En primer lugar, el supuesto de los Estados-nación induce a pensar que todos aquellos que lo conforman comparten una serie de características que les une y les distingue de los demás, de modo que en el caso de los gobiernos subnacionales gran parte de sus referentes 
identitarios serían compartidos -bajo este precepto teórico- con otras administraciones locales dentro del mismo Estado. Incluso si este supuesto fuera cuestionado, lo cierto es que los gobiernos subnacionales dentro del mismo Estado compartirán ciertos referentes, ya sea temporales — una historia o pasado común, un destino común-, territoriales ${ }^{6}$ y lingǘsticos, puesto que existe una lengua franca que termina por posicionarse e institucionalizarse como el idioma oficial o nacional.

No obstante, es posible que el lenguaje de la entidad sea distinto del resto del Estado-nación, del mismo modo que lo sean otros referentes, tales como la etnia o la religión, e incluso puede que compartan más referentes históricos - mitos, ancestros comunes-con otro pueblo o Estado. En este sentido, comienza a asomarse una dimensión cultural en cuanto al proceso de construcción de la autonomía subnacional, la cual no puede entenderse bajo la luz de un paradigma estrictamente estatocentrista (Keating, 1997). De este modo, la cuestión se complejiza al trasladar las cuestiones identitarias a las regiones o a los gobiernos subnacionales, ya que, a diferencia de la visión estatocéntrica, el grado de compartición y de diferenciación debe ser analizado a la luz de dos Otredades: la del Estado de origen y la del agente de destino de la actividad paradiplomática.

Dicha relación -que pareciera figurar en su modo elemental como tripartita- analizada desde una óptica constructivista suscita cuestionamientos tales como: ¿qué sucede cuándo la similitud identitaria es más fuerte entre la entidad subnacional y otros grupos que se encuentran fuera del Estado-nación?, ¿cómo incide esto en su práctica paradiplomática?, ¿cuáles son los principales modos de cristalización de estos grados de vinculación entre los gobiernos subnacionales y otros actores del sistema internacional? y ¿cuál es la respuesta de los

\footnotetext{
${ }^{6}$ El traspasamiento de autoridades -el Estado por encima del gobierno subnacional pero ambos con determinadas capacidades jurídicas en un mismo espacio- evidencia un territorio compartido. A su vez, este territorio funge como un referente identitario, desde sus componentes naturales (flora, fauna y demás condiciones topográficas), hasta los más urbanísticos (monumentos, plazas y el resto de condiciones arquitectónicas particulares).
} 
gobiernos centrales ante estos fenómenos? Con el fin de brindar algunas respuestas a esta serie de interrogantes, es necesario comenzar por una revisión del concepto mismo de paradiplomacia identitaria.

Paquin ha definido a la paradiplomacia identitaria como "una política exterior subestatal cuyo objetivo fundamental es el refuerzo o la construcción de la minoría nacional en el marco de un país multinacional" (2003, p. 12). Dicho autor ha señalado que el objetivo más importante de la paradiplomacia identitaria es el de ser reconocido internacionalmente como una nación (2003), o el de la protección cultural (2004), los cuales, a pesar de ser ciertos, reflejan solamente una perspectiva del fenómeno: la finalidad o el objetivo, en contraposición a la motivación.

Para esclarecer esta cuestión se debe señalar a qué se hace referencia cuando se confronta, de modo heurístico, la finalidad y la motivación. En este sentido, una actividad considerada paradiplomática puede buscar finalidades que van desde el desarrollo local, hasta la proyección de una imagen, así como otras más identitarias como la búsqueda del reconocimiento como nación, que es lo que las califica como tales de acuerdo a Paquin. Sin embargo, el factor identitario no solamente está vinculado a la finalidad sino que también está presente en la preferencia hacia un determinado actor para llevar a cabo estas acciones, esto es, la motivación o el motor.

De esta manera, en el primer caso de paradiplomacia identitaria por finalidad, un gobierno subnacional busca promoverse como una nación independiente del Estado del cual formaba parte; ésta se relaciona más con la conceptualización hecha por Paquin (2003, 2004). Por su parte, en el caso de paradiplomacia identitaria por motivación se hace referencia a un gobierno subnacional que intenta, simplemente como ejemplo, incrementar sus exportaciones con un actor con quien se comparten algunos referentes identitarios -ya sean históricos, lingüísticos, culturales o religiosos-. A diferencia del primero, en este caso la finalidad no es necesariamente identitaria, aunque también podría serlo, sino que la principal distinción radica en la existencia de un vínculo identitario que motiva la relación entre ambos. Lo anterior 
parte de uno de los supuestos más básicos del constructivismo donde se señala que "los actores actúan con base en los significados que los objetos tienen para ellos" (Wendt, 1996, p. 50), sosteniendo así que lo material está sujeto a la intencionalidad del agente y a la visión que tiene de sí mismo, del Otro y de su entorno.

Lo que ocurre bajo esta nueva lectura de la diplomacia identitaria es que cuando otro actor internacional comparte determinados rasgos con el gobierno subnacional en cuestión, el primero es visto de dos modos de manera simultánea: como un "Ellos" ajeno, pertenecientes a otro Estado o siendo otro Estado, y como parte del "Nosotros", compartiendo aspectos de una identidad colectiva. Ambas caras de este proceso originan la búsqueda de la interacción entre estos actores porque el grado de similitud identitaria es capaz de brindarles una serie de ventajas. Así, si se comparte un referente lingüístico, las negociaciones podrían ser más sencillas y eficaces; por otro lado, si se comparten referentes culturales, ambos podrían estar interesados en institucionalizar acuerdos de cooperación a favor de la preservación de ésta y sus tradiciones. Además, si el reconocimiento como parte del "nosotros" es mutuo, es altamente factible que ambas partes tengan mayor predisposición a la cooperación por el nivel de confianza e incluso, pudiera originarse un sentimiento de solidaridad y de responsabilidad hacia su contraparte con base en un sentido de identificación y pertenencia.

La Otredad y el componente relacional que se desprende de esta relación tripartita es quizá uno de los elementos fundamentales que merecen un mayor análisis en el campo de la paradiplomacia identitaria. En primer lugar, la Otredad -tanto como parte del "nosotros" como en su modalidad "ellos" o la mezcla de ambas - , moldea lo que Mouffe (2011) ha denominado "exterioridad constitutiva", la

\footnotetext{
7 Recuérdese que para la forma genérica descrita se hace referencia a una relación tripartita, esto es un sujeto -gobierno subnacional- frente a dos otredades: el gobierno central y el actor con quien se realiza la actividad paradiplomática. Así, cuando se hace referencia a la Otredad, ésta puede dirigirse hacia cualquiera de los dos casos y las figuras "ellos", y "nosotros" pueden aplicarse a cada uno por separado o ambas pueden encontrarse dentro de un mismo caso.
} 
cual refiere a la precondición de entes externos como parte de la identidad del actor. En otras palabras, el sentido de pertenencia o de diferenciación hacia cualquier Otredad contribuye a moldear -ya sea interiorizando o rechazando atributos- la identidad del agente, al grado que hay quienes afirman que la identidad se mantiene más por las relaciones sociales que por sus propiedades intrínsecas (Mitzen, 2006).

Ahora, dentro de un enfoque relacional esto es sólo una parte del proceso; no basta que el actor sienta o represente una determinada identidad, sino que ésta le debe ser reconocida por el Otro o los Otros. Al respecto, la identidad y la seguridad ontológica ${ }^{8}$ que se desprende en gran medida de ella, dependen de este reconocimiento por su contraparte. Así, cuando la Otredad -ya sea una o ambas partes de la relación tripartita- responde reconociendo la identidad del actor, éste tendrá una mayor seguridad y su sentido identitario se verá reforzado. Por el contrario, cuando la Otredad no responde a la identidad del actor, esto es que no le reconoce como tal, puede enfrentarse a una ansiedad ontológica. ${ }^{9}$ Sin afán de penetrar en esta temática, lo que debe destacarse para nuestros fines es que la paradiplomacia identitaria gestada por un gobierno subnacional y otro actor internacional se verá impulsada por la heteroadscripción, es decir, cuando su contraparte le reconozca la compartición de los atributos y se pueda generar un sentimiento de colectividad. ${ }^{10}$

8 La "seguridad ontológica" es un término de reciente uso en las Relaciones Internacionales que se desprende del trabajo de Anthony Giddens (1995). Al respecto, "ser ontológicamente seguro es poseer en el nivel del inconsciente y de la conciencia práctica, respuestas a cuestiones existenciales fundamentales que se plantea de alguna manera toda vida humana" (p. 66); por lo que la identidad forma parte de estos cuestionamientos existenciales aún si tratamos con agentes colectivos.

$9 \quad$ Esta situación puede traducirse en la experiencia de una identidad que no encuentra un reconocimiento en el Otro. Durante estos casos donde hay una pérdida en la predictibilidad, el agente puede verse desorientado en un entorno cognitivo nuevo en el cuál no sabe cómo debe de actuar. Se recomienda la lectura de Mitzen (2006) y Steele (2008) para profundizar en los términos de "seguridad ontológica" y "ansiedad ontológica".

10 Si bien el concepto de heteroadscripción es criticado por autores escépticos con respecto a los términos subjetivistas (Gómez García, 2001), se ha considerado pertinente para acentuar la intersubjetividad del fenómeno. Así, Giménez (2004) ha señalado que la identidad no es algo únicamente intrínseco sino que tiene un rasgo relacional, que puede ser mejor aprehendido bajo este término o mediante aquél usado por el autor: 'hetero-reconocimiento'. 
Por su parte, cuando el proceso de heteroadscripción no es eficaz y la contraparte no reconoce en el gobierno subestatal la compartición de una identidad colectiva, éste puede responder a la ansiedad ontológica con varias estrategias que esperan impulsar una determinada imagen; entre éstas sobresalen la repetición de comportamientos y discursos sobre su identidad, así como el mantenimiento de relaciones tanto de amistad como de distanciamiento. De este modo, si el Otro no respondiera del modo previsto a la identidad del agente subnacional, las acciones anteriores podrían establecer un cambio en la percepción que tiene el primero del segundo. ${ }^{11}$ Sin embargo, se debe destacar que, aún en un plano meramente teórico, esto difícilmente ocurriría bajo esta particular lectura de la paradiplomacia identitaria, ya que si se observa desde la motivación, seguramente existirán algunos atributos identitarios que son compartidos previamente entre las partes; lo anterior tampoco sugiere una aproximación esencialista, sino plantea un supuesto para los casos revisados de paradiplomacia identitaria.

Estas formas alternativas de pertenencia, identificación y compartición de referentes plantean un desafío al proyecto nacional del gobierno central. En este sentido, cada vez son más los actores sociales que desarrollan sentimientos de pertenencia e identidades múltiples, las cuales reducen la homogeneidad nacional del Estado donde se ubican los colectivos subnacionales. Así, los espacios nacionales actuales muchas veces presentan proyectos antagónicos o insubordinados que no han encontrado un espacio de representación e identificación con el proyecto hegemónico nacional, ${ }^{12}$ de modo que esto origina la búsqueda y el desarrollo de relaciones con otros actores con quienes es mayor el grado de compartición de algunos referentes identitarios.

También cabe subrayar que la existencia de distintos proyectos identitarios no asume, necesariamente, la búsqueda de actividades con

\footnotetext{
11 Wendt (1999) ha denominado este proceso como alter-casting, el cual ocurre cuando un actor actúa en un modo particular para tratar de inducir en el Otro un tipo de comportamiento esperado.

12 Se sugiere la obra de Laclau (2011) para ahondar en el concepto de hegemonía y la competencia que ocurre con los proyectos rivales.
} 
miras a la independencia de la región. De hecho, este tipo de acciones son relegadas a los estudios de nacionalismo o de protodiplomacia, la cual, si bien tiene algunos rasgos similares con la paradiplomacia identitaria, debe cuidarse de ser puesta en consideración aparte; así, a menos que las actividades del gobierno subnacional evidencien la búsqueda de su independencia, su análisis podrá permanecer en el terreno paradiplomático.

La formulación teórica presentada hasta el momento ha intentado demostrar cómo las afinidades culturales son resortes poderosos para la movilización y la colaboración. Sin embargo, como quedará expuesto en los casos de estudio, existirán algunas ocasiones donde los lazos culturales no traigan consigo acercamiento ni cooperación. Por su parte, lo que es más frecuente es que el elemento identitario sirva para justificar cualquier acercamiento entre las partes y la toma de decisiones que se desprende de dicho proceso; así, en aquellos casos donde la identidad no constituya la motivación, al menos sirve para revestirla y legitimarla.

Asimismo, y de modo casi evidente, se debe recordar que, del mismo modo que la diplomacia de los Estados-nación no se conforma únicamente por componentes identitarios, las actividades paradiplomáticas de los gobiernos subnacionales tampoco presentan una única variable; consecuentemente, la identidad debe estudiarse como uno entre múltiples factores que motivan el acercamiento entre los agentes. Por lo anterior y con la finalidad de observar dicho factor es necesario estudiar las relaciones de un gobierno subestatal en relación con otros actores con los cuales existan elementos culturales e identitarios compartidos, lo cual se realizará para los casos de estudio ya señalados, tras presentar las categorías de análisis con las que serán abordados.

\section{Encuadre metodológico}

Para alcanzar los objetivos del presente artículo, se ha diseñado un sistema de clasificación que permita dilucidar los aspectos más elementales de la actividad paradiplomática identitaria. A partir de la 
revisión de la teoría se han establecido las categorías necesarias que permitan hacer un análisis comparativo entre los tres casos de estudio, los cuales ayudarán a evidenciar tanto las particularidades como las semejanzas. A continuación se presenta cada rubro, con una pequeña descripción en los casos que lo amerite:

a. Instrumentación jurídica: Refiere a los mecanismos legales que permiten a la entidad subnacional el ejercicio de su actividad internacional con cierta autonomía respecto al gobierno central.

b. Naturaleza del agente local o de origen: Especificidades de la principal entidad de estudio, misma que, dentro de los estudios de paradiplomacia, equivale generalmente a la figura del gobierno subnacional que emprende la acción.

c. Naturaleza de los agentes de destino: Repetición de la pormenorización anterior con respecto a la entidad con la cual se pretende desarrollar la actividad paradiplomática.

d. Relación con el Estado-nación de origen: Caracterización de la relación que se mantiene con el gobierno central del Estado del que forma parte.

e. Relación con el agente de destino: Caracterización de la relación mantenida con el Estado-nación, gobiernos o entidades seleccionados para el desarrollo de la actividad.

f. Atributo(s) identitario(s) compartido(s): Principal(es) motor(es) cultural(es) de la actividad paradiplomática.

g. Finalidad de la actividad: Perspectiva u objetivo con el que se aborda el rasgo identitario.

h. Limitaciones a la actividad paradiplomática: Categorización de los principales impedimentos.

i. Sucesos de coyuntura: eventos que propician la acción paradiplomática. ${ }^{13}$

\footnotetext{
13 Los sucesos de coyuntura figuran como una variable de bastante flexibilidad, cuya riqueza está encerrada en esta misma característica. Al respecto, el rasgo que permita incluir los fenómenos que se anuncian dentro de esta categoría es la incidencia que tienen con respecto a la tendencia que venía proyectándose en la actividad paradiplomática. Así, son eventos cuya ocurrencia provoca un giro radical -y positivo, a diferencia de los impedimentos- en la relación paradiplomática, independientemente de sus orígenes, sus espacios de acción o su duración.
} 
j. Estructura de la actividad paradiplomática: Aparato administrativo que se articula en torno a esta relación.

k. Institucionalización de la identidad: Materialización legal o concreción de acuerdos en este ámbito.

A continuación se describirán las experiencias de paradiplomacia entre los tres casos de estudio, para los cuales se tendrán en consideración a las categorías señaladas. Por su parte, el análisis comparativo será efectuado en el apartado posterior a las experiencias, una vez que los casos hayan sido enmarcados en sus respectivos contextos.

\section{Experiencias paradiplomáticas identitarias}

\subsection{La experiencia de Quebec con Francia}

Quizá uno de los casos más estudiados ha sido la actividad exterior de la región de Quebec, la cual constituye la provincia más grande de Canadá y que, a diferencia del resto del país, tiene como única lengua oficial el francés. En términos históricos, Quebec es reconocido de facto como una nación diferente desde la misma promulgación del Acta de Quebec en 1774; ello es reforzado mediante la aprobación del Acta Constitucional de 1791 que dividía el antiguo territorio francés en el Alto Canadá -anglófono- y el Bajo Canadá -francófono-, e incluso en el Acta de la Norteamérica Británica de 1867 (Calonge Velázquez, 2013). En este sentido, su historia ha sido marcada por una construcción nacionalista particular, caracterizada en ocasiones por luchas secesionistas y en paralelo con la propia del federalismo canadiense; todo ello le ha permitido ganar espacios político-administrativos dentro del marco legal del país, tanto que han sido reconocidos como una nación diferente dentro del territorio canadiense desde $2006 .{ }^{14}$

\footnotetext{
14 A la luz del devenir histórico nacionalista de Quebec, este reconocimiento federal otorgado en 2006 no es más que una consecuencia de los intentos secesionistas quebequenses de las últimas décadas del siglo veinte, ya que como bien menciona Keating (1997) el sentimiento identitario quebequense se origina desde la derrota francesa frente a la corona británica en 1759. Así, el reconocimiento de 2006 puede entenderse mejor como una solución paliativa a los diferentes episodios de intentos secesionistas e igualmente como parte del proceso evolutivo del propio federalismo canadiense.
} 
No obstante, el inicio de su agenda paradiplomática se sitúa a inicios de la década de 1960 bajo la llamada Revolución Silenciosa. Con base en ésta, es posible entender un marco de acción político-legal quebequense más activo y dinámico, pues ésta se apartaba del nacionalismo clero-nacionalista tradicional -como lo llama Keating (1997)- hacia uno más progresista y liberal en el que el gobierno de esta provincia y el sector privado debían catapultar la economía de Quebec. ${ }^{15}$ Este nuevo escenario permitió que el gobierno quebequense pudiera reclamar el derecho a conducir su propia política exterior y firmar acuerdos internacionales en campos dentro de su competencia; de hecho, la doctrina Gérin-Lajoie -expresada por dicho Ministro de educación- de 1965 manifiesta la determinación por ampliar las jurisdicciones internas hacia el exterior bajo la dirección de Quebec (López Vallejo, 2002).

La lucha que enfrentó el Gobierno quebequense y el Gobierno federal de Canadá puede resumirse en una serie de acuerdos y enmiendas, como aquéllos del Lago Meech (1980) y de Charlotte Town (1990), que no lograron más que un enardecimiento de los sentimientos nacionalistas de Quebec y que se expresaron en intentos secesionistas y en la promulgación de leyes contestatarias. Así, estos fueron materializados en los referendos realizados en 1980 y 1995 para votar por la separación de la provincia. Igualmente, las leyes como aquélla sobre el ejercicio de los derechos fundamentales y las prerrogativas del pueblo y del Estado de Quebec (2000) son una respuesta nacionalista quebequense a la promulgación de la Ley de Claridad a nivel federal (Calonge Velázquez, 2013). No obstante, dicha efervescencia nacionalista ha quedado estancada desde principios del siglo XXI, cuando en 2003 el Partido quebequense, de corte conservador, fue derrotado en las elecciones provinciales por el Partido liberal de Quebec, más inclinado al esquema federalista-. En épocas más recientes

\footnotetext{
15 En este ejercicio nacionalista de libre intercambio se vieron favorecidas las inversiones y el comercio con los Estados Unidos, de tal forma que con la posterior entrada en vigor del tratado comercial entre Canadá y Estados Unidos (1988) y aquél entre estos dos y México (1994), el mercado de exportación quebequense se desplazó desde el Canadá anglófono hacia el mercado estadounidense (Legaré, 2005).
} 
cabe destacar la última derrota electoral del partido conservador frente al partido liberal en abril de 2014; así, de acuerdo con López Basaguren (2014), la popularidad del movimiento independentista fue puesta en entredicho al obtener un 25,5\% del total de la elección. ${ }^{16}$

En consecuencia, el plano cultural del nacionalismo quebequense no ha estado exento de la incorporación de los elementos históricos y constitutivos franceses (Cuenca Miranda, 2013). A partir de la lectura histórica queda clara la distinción en torno a Quebec desde el fin de la guerra entre Francia y el imperio británico a finales de 1750. Dentro de ésta, resaltan tres elementos de su pasado francés: la lengua francesa, la religión católica y una clase social rural que se diferenciaba de la creciente burguesía anglófona instalada en Montreal (Keating, 1997). Como los últimos dos elementos entran en tensión con la perspectiva progresista de la revolución silenciosa, la lengua -el francés- es el componente que termina por ocupar un lugar central en la referencia identitaria (Thériault, 2008).

De este modo, la búsqueda quebequense por tener un mayor grado de incidencia en la política federal, así como su reconocimiento como una sociedad distinta, francófona, con una sola cultura y un derecho civil tradicional (Ruiz Robledo, 1993), han propiciado una especie de vacío jurídico visible en la actual constitución canadiense. ${ }^{17}$ En paralelo a este señalamiento, dicha acta constitutiva establece una distribución específica de poderes y responsabilidades en materia de relaciones internacionales, tanto a nivel federal como provincial, ${ }^{18}$

\footnotetext{
16 En este sentido, existen varios factores que coadyuvan a entender el estancamiento del soberanismo o separatismo quebequense, entre los que se destacan las transformaciones demográficas en la provincia, la incertidumbre económica respecto a una separación, y el énfasis de una agenda política relacionada con asuntos sociales (Emmerich, 2003; Changfoot \& Cullen, 2011).

17 En sentido estricto, corresponde a la Corte suprema canadiense resolver las prerrogativas y atribuciones específicas de las provincias. Así, las resoluciones que emite la Corte sobre intentos separatistas evidencian los vacíos de la Constitución. Por ejemplo, a partir de la resolución de la Corte suprema sobre la secesión de Quebec en 1998, el parlamento canadiense aprueba la Ley de Claridad para buscar una salida de corte federalista a las ambiciones separatistas de esta provincia (Calonge Velázquez, 2013).

18 Estas responsabilidades se enlistan en la sección 91 y 92 de la British North American
} 
limitando las decisiones del primero en los campos que competen a las provincias: cuestiones migratorias, manejo de los recursos naturales, salud, educación, cultura y medioambiente.

Por tanto, el grado parcial de autonomía ha generado que Quebec desarrolle sus relaciones al exterior, dentro de las cuales la experiencia con Francia se encuadra en una relación "directa y privilegiada" de más de 50 años. Ésta se entiende nuevamente a partir de la posición central que ocupaba el idioma francés en el proyecto de modernización de la revolución silenciosa. ${ }^{19}$ Dicha posición fue bien aprovechada para entablar una relación, pues el idioma constituía un repensar, expresado en el discurso gaullista de 1960, de la influencia francesa en Quebec para su propia construcción histórica como nación (Legaré, 2005; Morin, 2008). Bajo esta lógica, la lengua se ha constituido en un campo simbólico que da cabida a los intereses de los actores políticos quebequenses y franceses.

Para Quebec, Francia es un socio estratégico que ocupa un lugar particular en su política internacional y en su estrategia gubernamental con respecto a Europa. El establecimiento de la Masion du Québec en París en 1961 marca la formalización de la relación bilateral, la cual se expresa actualmente mediante dos dispositivos diplomáticos: la Delegación general de Quebec en París y el Consulado general de Francia en Quebec. Estos dispositivos son reconocidos por sus pares a partir de algunas prerrogativas diplomáticas usualmente concedidas a las embajadas y constituyen el corazón mismo de la relación francoquebequense. Junto con estos dos dispositivos, el Ministerio de Relaciones Internacionales y de la Francofonía coordina las acciones del

Act (BNA) de 1982, la cual ha sufrido importantes enmiendas como resultado de las diferentes concepciones del federalismo por parte de los gobiernos de las provincias (López Vallejo, 2002).

$19 \mathrm{Al}$ respecto hubo una clara politización de la lengua francesa en tanto que lograba dar correspondencia identitaria a los canadienses francófonos o quebequenses, como decidieron autodenominarse. Así, Thériault escribe sobre el estatus de la lengua francesa en los años 1960: "avanza claramente; [...] se convierte primero en lengua prioritaria, luego en lengua oficial de Quebec y tiende a transformarse en la lengua común de los quebequenses. Se separará cada vez más de la Iglesia y del grupo etnocultural francés” (2008, p. 320). 
gobierno de la provincia, de sus ministerios y organismos en Francia, permitiendo un contacto directo entre el primer ministro de Quebec y el presidente de la república francesa, como las reuniones bianuales que desde 1977 se realizan entre ambos personajes para convenir y adaptar los objetivos y prioridades de la relación a sus gobiernos.

En cuanto a la cooperación franco-quebequense destaca el fuerte impacto en la sociedad civil: la cultura, la educación, los intercambios universitarios, la juventud, la ciencia, la tecnología y las asociaciones entre colectividades territoriales francesas. Esta cooperación se genera a partir del trabajo de las siguientes esquemas: la Comisión permanente de cooperación (CPCFQ), la Oficina franco-quebequense para la juventud (QFQJ), el Consejo franco-quebequense de cooperación universitaria (CFQCU), el Grupo franco-quebequense de la cooperación económica (GFQCE), la Asociación Quebec-Francia y FranciaQuebec, y el Fondo para cooperación descentralizada (FFQDC), el cual ha impulsado diversas iniciativas con seis regiones francesas, ${ }^{20}$ denotando una evolución importante de la relación bilateral.

Los esquemas de colaboración han producido una movilización de recursos y personas, entre las que se destaca la creación de redes de intercambio y colaboración entre profesores, estudiantes, profesionistas, universidades, centros de investigación y artistas de ambas naciones (Ministerio de Relaciones internacionales y de la Francofonía, 2015), como lo demuestran numerosos reportes e informes. ${ }^{21}$ En materia económica, las inversiones representan el centro de la relación bilateral, por lo que no debiera sorprender que Francia sea el segundo inversionista más importante en Quebec, después de Estados Unidos. Por su parte, las empresas francesas han establecido

\footnotetext{
20 Alsacia, Aquitania, île-de-France, Midi-Pyrénées, Poitou-Charentes y Rhône-Alpes. Esta última representa el primer plan de acción firmado en 1994 por Quebec y una colectividad francesa (Ministerio de Relaciones Internacionales y de la Francofonía, 2015).

21 Estos pueden consultarse con facilidad en el sitio web del Ministerio de relaciones internacionales de Quebec (http://www.mrif.gouv.qc.ca/). Además en Québec-France Protait d'une relation en mowvement, informe publicado por el gobierno de Quebec en 2002 y 150 años de relaciones Francia-Quebec (2010), obra publicada por la CPCFQ, pueden revisarse con detalle estas experiencias de cooperación.
} 
más de 200 filiales en la provinicia canadiense, mientras que más de 100 empresas quebequenses se han instalado en Francia (Consulado general de Francia en Quebec, 2015).

A partir del establecimiento de las relaciones en 1964, Quebec y Francia han suscrito más de 70 acuerdos de cooperación hasta el año 2008, ${ }^{22}$ principalmente en educación, cultura, ciencia, relaciones comerciales y movilización profesional. En este sentido, uno de los últimos acuerdos firmados (octubre de 2008) es el que versa sobre el reconocimiento mutuo de cualificaciones profesionales, el cual permitió 81 arreglos para que éstas sean reconocidas en ambos territorios.

El despliegue de los esquemas, dispositivos, acuerdos y demás instrumentos de los que hace uso la relación bilateral, muestran la manera en que se ha diferenciado la provincia francoparlante con respecto al resto de Canadá. Además, la toma de conciencia de su situación histórica y el reconocimiento de dicho lazo con la población francesa, impulsa la unión de ambas. ${ }^{23}$ Por su parte, la postura de Francia es recíproca al punto que legitima este proceso y los encuentros que se desprenden del mismo.

Finalmente, es importante destacar la existencia de obstáculos para la consolidación de la actividad paradiplomática hacia Francia, particularmente a partir de los momentos de fervor sececionistaindependentista por parte de Quebec, que pugnan por una ampliación de sus facultades legales, los cuales generan conflictos con el gobierno federal. Si bien éstos no han conseguido un respaldo de la mayoría, lo cierto es que han producido vías de expresión alternas como los actos terroristas del Frente de Liberación de Quebec durante los sesenta (López Vallejo, 2002). Aunado a estos dos factores,

\footnotetext{
22 Para consultar con detalle estos acuerdos, el sitio web del Ministerio de relaciones internacionales de Quebec (http:/ /www.mrif.gouv.qc.ca/) y del Ministerio de Asuntos exteriores y Desarrollo internacional de Francia (http://www.diplomatie.gouv.fr/) permiten acceder a ellos.

23 Estas palabras resumen los discursos de Jean Lesage, ex Primer ministrio quebequés, y de Charles de Gaulle, ex presidente francés, pronunciados en París en 1961 (Gobierno de Quebec, 2002).
} 
el posicionamiento del que goza Francia frente a la provincia ha suscitado posturas condenatorias por parte del gobierno canadiense al argumentar la exclusividad del mismo en la conclusión de tratados y acuerdos internacioales (Thérien, Bélanger, \& Gosselin, 1996). Sin embargo, estos obstáculos no han impedido que ambas partes sigan formalizando su relación, la cual parece legitimarse sobre la base de un mutuo reconocimiento identitario.

\subsection{La cooperación transfronteriza de los vascos}

La experiencia de las zonas vascas representa una situación más compleja. Al respecto, cabe mencionar primeramente que los Pirineos forman una frontera natural entre España y Francia, coadyuvando en la división fronteriza de dicha comunidad. Al norte de los Pirineos, el país vasco francés o Iparralde está localizado entre los distritos de Bayona, Oloron-Sanite-Marie y $\mathrm{Pau},{ }^{24}$ todos los cuales se encuentran en el Departamento de los Pirineos Atlánticos dentro de la Región de Aquitania. Por su parte, al sur de los Pirineos, el país vasco español o Hegoalde, está conformado por la Comunidad Floral de Navarra y las provincias de la Comunidad Autónoma del País Vasco, Álava, Vizcaya y Guipúzcoa. Tanto Navarra como el País Vasco español y los distritos del País Vasco francés, han conformado un espacio cultural histórico denominado Vasconia o Euskal Herria, ${ }^{25}$ el cual, si bien se presenta dividido por una frontera entre dos Estados, ha producido actividades paradiplomáticas por parte de sus respectivos gobiernos en el marco de una cooperación transfronteriza.

A partir de este contexto, el objetivo es abordar el despliegue paradiplomático que se desprende principalmente por parte de los gobiernos del País Vasco francés, con respecto a las comunidades de Navarra o del País Vasco. El punto de partida para entender esta experiencia

\footnotetext{
24 Dentro de ellos se localizan las colectividades que históricamente han constituido el País Vasco francés: Labourd, Basse-Navarre y Soule.

25 En 1659 la frontera entre Francia y España fue definida mediante el tratado de los Pirineos. Desde entonces, cada región vasca se ha desarrollado en relación a la construcción de sus respectivos Estados-nación.
} 
paradiplomática es el mismo proceso de integración europea, el cual provocó la descentralización en el territorio francés para la década de los ochenta (Ley de descentralización de 1982). Dicha ley ha dado lugar a la construcción de políticas de cooperación transfronteriza, que se han intensificado con la apertura de fronteras del Tratado de Maastricht, y gracias a nuevas herramientas jurídicas de cooperación, como los fondos y programas de colaboración. ${ }^{26}$

El País Vasco francés ha motivado la relación con sus contrapartes españoles en el marco del Tratado de Bayona de 1995 y las disposiciones del Código General de las colectividades territoriales. ${ }^{27} \mathrm{Si}$ bien la instrumentación jurídica francesa se estructura hasta la firma de dicho tratado, la voluntad política de esta región para definir su desarrollo con base en su identidad comienza a finales de 1980, con la apertura de algunos canales de cooperación, como la firma del Protocolo de Cooperación Transfronteriza entre la comunidad autónoma Euskadi y Aquitania, a la cual se adheriría Navarra en 1992. Sin embargo, tras algunos problemas entre el País Vasco español y Navarra, éste decide retirarse unilateralmente en el año $2000 .{ }^{28}$ Ese mismo año, la comunidad Vasca y Aquitania retomarían el primer convenio para continuar con la cooperación, mientras que un nuevo convenio bilateral fue firmado entre Navarra y Aquitania. A su vez, dichos convenios han sido dotados de un financiamiento para crear un fondo común, que en el caso francés es provisto del mismo gobierno central. De este modo, la región francesa ha proseguido con

\footnotetext{
26 Véase el último reporte sobre la acción exterior de las colectividades territoriales francesas, presentado por el Ministerio de Asuntos Exteriores de Francia en 2013.

27 Ambas figuras le han permitido establecer estructuras jurídicas comunes con las dos Comunidades españolas, ya sea bajo el esquema francés o español, respetando el derecho interno y las competencias de cada colectividad (Consejo de Desarrollo del País Vasco, 2003).

28 De acuerdo a Filibi (2009), la decisión de Navarra obedecía a razones ideológicas. A este respecto, el presidente en turno de la Comunidad de Navarra intentaba desvincularla de la esfera vasca. Debe señalarse igualmente que, a pesar de este desencuentro, las comunidades vascas españolas tienen un Protocolo Interautonómico de Colaboración que data de 2009, donde se presenta un proyecto cultural que involucra la colaboración con la región francesa con miras a fomentar el idioma euskera (Protocolo General de Colaboración entre la Comunidad Autónoma Vasca y la Comunidad Floral de Navarra, 2009, p. 9).
} 
las actividades de cooperación a dos vías, esto es, de modo separado con la Comunidad Vasca y con Navarra.

Con respecto a su relación con Navarra, sobresalen dos proyectos: por un lado, desde 2002 está en marcha el desarrollo turístico de Xareta -territorio cultural, histórico y geográfico que integra dos comunas vascas francesas y dos más españolas-, el cual atiende acciones de interés común relacionadas con el desarrollo económico, de transportes y comunicación, infraestructura, medioambiente y planificación del territorio (Consejo de Desarrollo del País Vasco, 2003). Por otro lado, destaca el Acuerdo Marco de Cooperación Transfronteriza, suscrito por el Consejo General de Pirineos Atlánticos y el gobierno de Navarra en marzo de 2011, el cual engloba cuestiones tales como inversión, empleo, investigación, turismo, intercambios lingüísticos y culturales, entre otros.

Por su cuenta, la cooperación con respecto al País Vasco español ha desarrollado dos estructuras de gran peso para las regiones: la Eurociudad vasca Bayona-San Sebastián y el Consorcio Bidasao-Txingudi. La primera comienza a desarrollarse desde inicios de 1993 bajo la forma de un protocolo de cooperación que tiene como objetivo posicionar la conurbación Bayona-San Sebastián competitivamente en el sistema urbano regional y europeo. ${ }^{29}$ En 2011 este esquema incorporó al Consorcio Bidasao-Txingudi, el cual agrupa a la colectividad francesa de Hendaye y a las ciudades españolas de Irun y Hondarrabia. Bajo esta estructura, dichas localidades han organizado manifestaciones culturales $^{30}$ en común, que permiten a sus poblaciones conocerse mejor, trabajar en conjunto sobre cuestiones de urbanismo y difundir estas acciones en las tres lenguas -francés, español y euskera- (Consejo de Desarrollo del País Vasco, 2003; Gayon, 2011).

\footnotetext{
29 Específicamente, este proyecto busca la construcción de una plataforma atlántica de intermodalidad, comunicación e información, así como la protección de su patrimonio natural (Consejo de Desarrollo del País Vasco, 2003).

30 Algunos ejemplos son las Txingudi Egunak (jornadas de Txingudi), la Txingudi Korrika (carrera de Txingudi) y las fiestas de la bahía de Txingudi.
} 
Estos ejemplos reflejan cómo la principal área de cooperación radica en la unión de las dos regiones, a través de acercamientos culturales y un mejoramiento en la infraestructura y en los sistemas de comunicaciones. Esta situación permite la asociación de numerosos actores institucionales; del lado francés, el departamento de los Pirineos Atlánticos y la región de Aquitania trabajan bajo estructuras específicas que agrupan al Consejo General de los Pirineos Atlánticos, el Consejo regional de Aquitania y el Consejo de Desarrollo del País Vasco, ${ }^{31}$ así como al Instituto Cultural Vasco y a la Cámara de Comercio e Industria transfronteriza Bihartean. ${ }^{32}$ Estos actores encuentran su contraparte del lado español en la Diputación Floral de Guipúzcoa y el gobierno vasco, y el de Navarra; los tres de naturaleza política. De esta manera, más que las propias provincias, son las competencias de las que en términos de cooperación dispone el gobierno de la Comunidad del País Vasco las que permiten el desarrollo de estos proyectos con los actores de lado francés.

Aunque la actividad exterior del País Vasco francés ha sido fuertemente desarrollada, también encuentra fuertes limitaciones al observar la amplia gama de competencias y financiamiento de sus contrapartes españolas. En este sentido, el País Vasco y Navarra son capaces de tener incidencia en prácticamente todos los aspectos de la vida de la región. Por su parte, el encuadre jurídico francés mantiene una subordinación de sus competencias administrativas, que se ven expresadas mediante el presupuesto ejercido por el Consejo general y el Consejo Regional en relación a los actores españoles. ${ }^{33}$ Otro obstáculo de gran relevancia que se desprende de esta relación está vinculado con las acciones terroristas de ETA; en este sentido,

\footnotetext{
31 Sus objetivos son contribuir al desarrollo del País Vasco, intervenir en la ordenación del territorio e impulsar la cooperación transfronteriza (Gayon, 2011). Dichas instituciones son financiadas por el gobierno central y están subordinadas a las estructuras políticoadministrativas del estado francés: departamento y región.

32 Esta fue creada por iniciativa de las Cámaras de Comercio de Bayona y de Guipúzcoa para trabajar en asuntos de naturaleza económica interregional.

33 En 2002, tanto el Consejo general como el Consejo regional recibían un presupuesto significativamente inferior al ejercido por la Diputación y las comunidades españolas (Consejo de Desarrollo del País Vasco, 2003). La situación no es diferente actualmente.
} 
la presencia de dicho grupo terrorista ha generado desconfianza por parte de la sociedad vasca francesa. Sumado a ello, el tipo de discursos políticos de los distintos partidos nacionalistas de la región española generan continuamente cierto recelo entre los dirigentes que se ubican del lado francés.

\subsection{El Kurdistán iraquí y el resto de la diáspora}

Las actividades paradiplomáticas del Kurdistán iraquí se remontan al periodo previo a la obtención de su autonomía. Al respecto, los kurdos iraquíes obtuvieron una independencia de facto tras los acontecimientos desatados por la guerra del Golfo de 1991 (Lundgren, 2007), que sirvió para comenzar a establecer ciertas relaciones con otros actores. Así, con la finalidad de posicionarse como los representantes de la región, los dos partidos predominantes —el Partido Democrático de Kurdistán (KDP) y la Unión Patriótica de Kurdistán (PUK) - buscaron relacionarse con los gobiernos vecinos, llegando incluso a establecer oficinas de representación en Turquía desde principios de los años 90 (Lundgren, 2007), a pesar de que una guerra civil era desatada por ambas organizaciones durante dicha década.

Esta situación mantendría las tensiones políticas y dividiría a ambas partes hasta la caída de Saddam Hussein. Posteriormente, con la promulgación de la nueva constitución del Estado iraquí en 2003, se formaliza jurídicamente la unicidad y la relativa autonomía de la región kurda. ${ }^{34}$ No obstante, dicha autonomía queda en cierto modo subordinada al gobierno central de Bagdad, particularmente en relación a la disposición de recursos naturales y energéticos; de igual modo, la política exterior de la región requiere estar coordinada con la del gobierno central. De cualquier modo, dicha acta constitutiva inaugura el inicio de su actividad paradiplomática desde un sentido canónico del término.

\footnotetext{
34 De acuerdo a el-Dessouki (2012), el acta constitutiva iraquí reconoce a Kurdistán como una región federal; además, le reconoce una identidad propia, reflejándose lo anterior en la inclusión del uso del idioma kurdo como uno de los dos idiomas oficiales.
} 
Al respecto, la paradiplomacia que se desprende del Gobierno Regional de Kurdistán (GRK en adelante) con respecto a los kurdos de Irán, Siria y Turquía es compleja y ambivalente. Por un lado, es complicada debido a factores como las divisiones políticas, las injerencias externas y la heterogeneidad cultural. Respecto a las primeras, existe una gran cantidad de partidos políticos, grupos armados, facciones y demás colectividades que dificultan el alcance de acuerdos, tanto a nivel kurdo-iraquí como a nivel transfronterizo, ya que cada uno tiene motivaciones e ideologías distintas (Kelly, 2010; Villellas, 2014). En segundo lugar, los gobiernos de Turquía, Siria, Irán y el mismo Irak, se han mostrado vigilantes y han canalizado un sinnúmero de esfuerzos para evitar que sus poblaciones kurdas puedan encontrar los caminos necesarios para una colaboración pan-kurdista. Asimismo, dichos gobiernos se han aliado con organizaciones kurdas ubicadas en los países vecinos para desequilibrarlos, tal como ha sido el caso del apoyo brindado por Siria e Iraq al Partido de los Trabajadores del Kurdistán (PKK, por sus siglas en kurdo), el acercamiento de Saddam Hussein con el KDP o el soporte que ha recibido el PUK por parte del gobierno iraní.

De igual modo, las localidades kurdas en Turquía e Irán no tienen la misma autonomía que el GRK para llevar a cabo sus relaciones internacionales, como tampoco lo tenían los kurdos sirios antes de la guerra civil, lo que dificulta cualquier aproximación inter-kurda. Bajo este panorama, los canales de comunicación se realizan frecuentemente por medio de los gobiernos nacionales o, en su defecto, a través de los partidos políticos que, cabe recordar, son sumamente prolíficos. Por último, en relación a la heterogeneidad cultural, existen rivalidades tribales que no han sido superadas, así como la presencia de distintos dialectos, lo cual genera que muchos kurdos no se entiendan entre sí o que se sientan más cómodos en las lenguas locales de sus países de origen (Arakelyan, 2013).

Además, respecto a la ambivalencia, el GRK no muestra un apoyo evidente ni implícito a las sociedades kurdas ubicadas en los países vecinos. Por un lado, su sitio oficial de relaciones exteriores hace algunas referencias respecto a la diáspora kurda, pero separando a la 
diáspora kurdo-iraquí del resto de los kurdos. Además, aunque señala su preocupación por la lucha de la población kurda, menciona que tiene voluntad de apoyar solamente a los partidos políticos kurdos que adopten los principios de la democracia y el pacifismo. Asimismo, el GRK enfatiza su carácter no intervencionista para esta zona. Sumado a ello, de las 13 representaciones internacionales con las que cuenta, sólo una de éstas se localiza en Irán, mientras que Turquía y Siria carecen de éstas. ${ }^{35}$

Así, hasta el momento, es evidente que la paradiplomacia manejada con las localidades kurdas vecinas puede categorizarse como escasa e incluso desfavorable; por el contrario, es viable afirmar que los mayores esfuerzos han sido destinados a desarrollar las relaciones con los gobiernos de Turquía e Irán, con un interés prácticamente nulo hacia Siria. Es por ello que, de acuerdo a Mohammed y Owtram (2014), la paradiplomacia que se desprende del Kurdistán iraquí tiene una orientación más económica que política o cultural, de modo que no es sorprendente que el GRK busque afianzar sus relaciones comerciales con el gobierno turco, a pesar de la situación de la población kurda en dicho país.

Lo anterior no es un asunto menor, particularmente cuando "el GRK contabiliza la mitad del comercio de Turquía con Iraq, el cual es el segundo socio comercial de Turquía después de Alemania" (Park, 2012, p. 111). De hecho, la relación entre éstas es tan fuerte que las compañías turcas conformaban un 55\% de las compañías extranjeras que operaban en la zona para el 2012 (Zulal, 2012). De igual modo, sobresale la firma de acuerdos que posibilitan la exportación de crudo (el-Dessouki, 2012) y la posibilidad de crear oleoductos hacia Turquía con miras a expandirse al mercado europeo (Villellas, 2014). Debido a lo anterior no resulta extraño que durante 2008, tanto el GRK como Turquía e Irak hayan suscrito un mecanismo de cooperación que pretendía erradicar la presencia del PKK en dicha región

\footnotetext{
35 La demarcación de su política exterior y el establecimiento de sus representaciones internacionales pueden consultarse en el sitio web del Departamento de Relaciones Exteriores del GRK (wwm.dfr.krg.org).
} 
(Charountaki, 2012), lo cual supondría un revés empírico a los supuestos de la paradiplomacia identitaria.

Si bien esta situación podría hacer suponer que la importancia de la cultura en los lazos paradiplomáticos es mucho menor que la relevancia que tienen los recursos y el comercio para el GRK, ello no es totalmente cierto. A diferencia de los dos casos anteriores, la centralidad de la cultura en esta relación se muestra bajo un aspecto totalmente diferente: a modo de legitimidad. Así, la identidad kurda es lo que le provee al GRK de la legitimidad necesaria para desarrollar canales paradiplomáticos con los gobiernos locales, con miras a presentarse como interlocutor o pacifista y de ese modo incrementar su importancia a nivel regional e internacional; los llamados al cese al fuego que el GRK ha solicitado al PKK son una muestra de lo anterior. Así, el Kurdistán iraquí quizá no busca tanto preservar o impulsar una cultura, como tampoco vincularse con aquellos con los que comparte dicha identidad, sino que para este gobierno subnacional la identidad funge como un medio que le sirve para otros fines.

Debe señalarse que esta situación ha cambiado en los últimos tres años a raíz de dos eventos que, irónicamente, han favorecido e intensificado las relaciones entre los actores internacionales representantes de los kurdos. Por un lado, la guerra civil en Siria propició la organización de la conferencia de Erbil en 2013, que suponía la participación de "600 delegados de más de 40 partidos kurdos de los cuatro países [...] por primera vez” (Synovitz, 2014, p. 3), por lo que ésta llegó a considerarse como una "oportunidad histórica" (Villellas, 2014, p. 2). Sin embargo, después de tres retrasos en su convocatoria, ésta fue pospuesta indefinidamente alegando problemas técnicos y políticos. Por su parte, el surgimiento y el apoderamiento del Estado Islámico (EI en adelante) ha supuesto una amenaza para toda la población kurda, principalmente la que se localiza en Siria e Irak. Lo anterior ha propiciado esfuerzos conjuntos que se han visto materializados en la ayuda del PKK a los peshmerga (guerrilleros kurdos iraquíes), algo que hubiera sido impensable años atrás cuando el Gobierno del Kurdistán instaba al PKK a un cese al fuego y a la entrega de sus armas (el-Dessouki, 2012; Park, 2012). 
En consecuencia, el papel del EI conllevó una mayor cohesión entre la comunidad kurda, otrora tan fragmentada. Ha sido tan relevante el papel de este fenómeno que éste queda evidenciado en comentarios como el que se desprende de un miembro del partido Unión Patriótica de Kurdistán, "[el Estado Islámico] es nuestro enemigo común... enfrentarnos a su terror nos ha reunido" (citado en Assir, 2014, p. 5). Así, a pesar de no contar con un despliegue institucional ni de haber formalizado marcos de cooperación como los señalados en los casos anteriores, la relación existente entre los kurdos todavía puede aprovecharse partiendo de la posibilidad de una mayor autonomía de los kurdos sirios, así como de la reciente unión de este gran colectivo ante la amenaza del EI.

\section{Resultados}

Con la finalidad de contar con una mejor lectura de los tres casos de estudio, a continuación se presenta una tabla que ilustra a modo comparativo los aspectos más sobresalientes para el análisis de la paradiplomacia identitaria:

Tabla 1. Cuadro comparativo de los tres casos mediante el uso de las categorías de estudio

\begin{tabular}{|l|l|l|l|}
\hline \multicolumn{1}{|c|}{ Categorías } & \multicolumn{1}{|c|}{ Quebequenses } & \multicolumn{1}{c|}{ Vascos franceses } & \multicolumn{1}{c|}{ Kurdos iraquíes } \\
\hline $\begin{array}{l}\text { Instrumenta- } \\
\text { ción jurídica }\end{array}$ & $\begin{array}{l}\text { Prerrogativas constitu- } \\
\text { cionales, frecuentemente } \\
\text { no explícitas, del sistema } \\
\text { federal canadiense. }\end{array}$ & $\begin{array}{l}\text { Único caso no federal ni } \\
\text { autónomo. Dependencia } \\
\text { del gobierno central } \\
\text { en materia de política } \\
\text { exterior. }\end{array}$ & $\begin{array}{l}\text { Autonomía en asuntos } \\
\text { internos, pero subordi- } \\
\text { nación al gobierno cen- } \\
\text { tral en ciertos asuntos } \\
\text { externos. }\end{array}$ \\
\hline $\begin{array}{l}\text { Naturaleza del } \\
\text { agente local }\end{array}$ & $\begin{array}{l}\text { Provincia federal con re- } \\
\text { conocimiento como na- } \\
\text { ción dentro de Canadá. }\end{array}$ & $\begin{array}{l}\text { Colectividad territorial } \\
\text { vincias contiguas que no } \\
\text { constituyen una entidad } \\
\text { administrativa francesa. }\end{array}$ & $\begin{array}{l}\text { Región federal autóno- } \\
\text { provincias contiguas. }\end{array}$ \\
\hline $\begin{array}{l}\text { Naturaleza } \\
\text { del agente de } \\
\text { destino }\end{array}$ & $\begin{array}{l}\text { Estado-nación con reco- } \\
\text { nocimiento internacio- } \\
\text { nal: Francia. }\end{array}$ & $\begin{array}{l}\text { Gobiernos autónomos } \\
\text { españoles: País Vasco y } \\
\text { Navarra. }\end{array}$ & $\begin{array}{l}\text { Provincias kurdas de } \\
\text { Irán, Siria y Turquía que } \\
\text { no gozan de autonomía. } \\
\text { Partidos políticos kurdos } \\
\text { de dichas regiones. }\end{array}$ \\
\hline
\end{tabular}

Continúa 


\begin{tabular}{|c|c|c|c|}
\hline Categorías & Quebequenses & Vascos franceses & Kurdos iraquíes \\
\hline $\begin{array}{l}\text { Relación con } \\
\text { el Estado de } \\
\text { origen }\end{array}$ & $\begin{array}{l}\text { Repetidamente proble- } \\
\text { mática, en ocasiones con } \\
\text { intentos secesionistas. }\end{array}$ & $\begin{array}{l}\text { Encuadre de sus re- } \\
\text { laciones exteriores } \\
\text { en el derecho interno } \\
\text { (político-administrativo) } \\
\text { francés. }\end{array}$ & $\begin{array}{l}\text { Subordinación en mate- } \\
\text { ria de política exterior. } \\
\text { Gestos protodiplomáti- } \\
\text { cos inexistentes. }\end{array}$ \\
\hline $\begin{array}{l}\text { Relación con } \\
\text { el agente de } \\
\text { destino }\end{array}$ & $\begin{array}{l}\text { Bilateral con dispositivos } \\
\text { diplomáticos específicos. }\end{array}$ & $\begin{array}{l}\text { Cooperación transfron- } \\
\text { teriza. }\end{array}$ & $\begin{array}{l}\text { Problemática, con escasa } \\
\text { concreción de acuerdos. } \\
\text { Supeditada a las eventua- } \\
\text { lidades. }\end{array}$ \\
\hline $\begin{array}{l}\text { Atributo(s) } \\
\text { identitario(s) } \\
\text { compartido(s) }\end{array}$ & $\begin{array}{l}\text { Referente mayoritaria- } \\
\text { mente lingüístico. }\end{array}$ & $\begin{array}{l}\text { Referente étnico, con } \\
\text { énfasis en la lengua } \\
\text { compartida. } \\
\text { Referente territorial. }\end{array}$ & Referente étnico. \\
\hline $\begin{array}{l}\text { Finalidad de } \\
\text { la actividad }\end{array}$ & $\begin{array}{l}\text { Desarrollo de la región a } \\
\text { partir del reconocimien- } \\
\text { to como una sociedad } \\
\text { diferenciada (nación) } \\
\text { dentro de Canadá. }\end{array}$ & $\begin{array}{l}\text { Proyectos políticos, co- } \\
\text { merciales y culturales que } \\
\text { posicionen a la región a } \\
\text { nivel urbano y europeo. }\end{array}$ & $\begin{array}{l}\text { Obtención de legitimi- } \\
\text { dad para presentarse } \\
\text { como mediador entre los } \\
\text { gobiernos vecinos y sus } \\
\text { poblaciones kurdas. }\end{array}$ \\
\hline $\begin{array}{l}\text { Limitaciones a } \\
\text { la actividad }\end{array}$ & $\begin{array}{l}\text { - Movimientos secesio- } \\
\text { nistas que han origina- } \\
\text { do recelo por parte del } \\
\text { gobierno francés. } \\
\text { - Ausencia de atribucio- } \\
\text { nes constitucionales } \\
\text { respecto a la acción } \\
\text { internacional de las } \\
\text { provincias. }\end{array}$ & $\begin{array}{l}\text { - Ideologías distintas } \\
\text { con determinados } \\
\text { proyectos políticos. } \\
\text { - Presencia de grupos } \\
\text { terroristas. } \\
\text { - Contradicciones en la } \\
\text { legislación francesa. } \\
\text { - Financiamiento pro- } \\
\text { veniente del estado } \\
\text { francés. }\end{array}$ & $\begin{array}{l}\text { - Rivalidades tribales. } \\
\text { - Ideologías e intereses } \\
\text { distintos. } \\
\text { - Alta proliferación de } \\
\text { grupos. } \\
\text { - Estados vecinos } \\
\text { (Turquía, Irán, Siria) } \\
\text { vigilantes y a veces } \\
\text { obstaculizadores. } \\
\text { - Presencia de grupos } \\
\text { terroristas. }\end{array}$ \\
\hline $\begin{array}{l}\text { Sucesos de co- } \\
\text { yuntura }\end{array}$ & $\begin{array}{l}\text { - Revolución silenciosa. } \\
\text { - Estado francés. } \\
\text { - Desaparición de actos } \\
\text { terroristas. }\end{array}$ & $\begin{array}{l}\text { - Proceso de integra- } \\
\text { ción europea. } \\
\text { - Descentralización del } \\
\text { Estado francés. }\end{array}$ & $\begin{array}{l}\text { - Guerra civil en Siria. } \\
\text { - Aparición del EI. }\end{array}$ \\
\hline $\begin{array}{l}\text { Estructura de } \\
\text { la actividad } \\
\text { paradiplomá- } \\
\text { tica }\end{array}$ & $\begin{array}{l}\text { - Ministerio de Relacio- } \\
\text { nes Internacionales y } \\
\text { de la Francofonía. } \\
\text { - Delegación general de } \\
\text { Quebec en París. } \\
\text { - Consulado general de } \\
\text { Francia en Quebec. }\end{array}$ & $\begin{array}{l}\text { - Consejo de Desarrollo } \\
\text { del País Vasco. } \\
\text { - Eurociudad vasca } \\
\text { Bayona-San Sebastián. } \\
\text { - Consorcio Bidasao- } \\
\text { Txingudi. }\end{array}$ & $\begin{array}{l}\text { - Una oficina de repre- } \\
\text { sentación en Irán. } \\
\text { - Consulados generales } \\
\text { de Irán y Turquía en } \\
\text { Kurdistán. }\end{array}$ \\
\hline $\begin{array}{l}\text { Instituciona- } \\
\text { lización de la } \\
\text { identidad }\end{array}$ & $\begin{array}{l}\text { Numerosos acuerdos, } \\
\text { más de } 70 .\end{array}$ & $\begin{array}{l}\text { Acuerdo Marco de Coo- } \\
\text { peración Transfronteriza. }\end{array}$ & $\begin{array}{l}\text { Prácticamente inexis- } \\
\text { tente. }\end{array}$ \\
\hline
\end{tabular}

Fuente: Elaboración propia. 
Los resultados de la tabla anterior permiten inferir algunas aproximaciones a este fenómeno. $\mathrm{Al}$ respecto, se puede comenzar señalando que en todos los casos existe un espacio de diferenciación en relación a la comunidad nacional de la que forman parte. Igualmente, ambas partes reconocen la compartición de ciertos atributos identitarios y reivindican este tipo de lazos mediante el desarrollo de un canal paradiplomático, independientemente del éxito que éste logra.

Asimismo, aunque la instrumentación jurídica es importante para el desarrollo de los lazos paradiplomáticos, ésta no necesariamente los propicia. Bajo esta lógica, los gobiernos subnacionales intentarán desarrollar sus relaciones con el exterior, ya sea que cuenten o no con el encuadre jurídico necesario que les permita hacerlo. Además, no hay una estructura legal única: si bien todas fluyen hacia una misma dirección produciendo un mismo hecho, éstas evolucionan a raíz de circunstancias muy particulares. No obstante, también debe mencionarse que un marco jurídico permisivo siempre favorecerá este tipo de canales, tal como queda evidenciado con los quebequenses y con los kurdos tras el establecimiento de la constitución iraquí de 2003.

Bajo este esquema, el papel que adoptan los gobiernos centrales puede minar con mayor fuerza el desarrollo de los canales paradiplomáticos que un marco legal rudimentario. En este sentido, cuando el tema de la identidad se encuentra de por medio en las relaciones exteriores de un gobierno subestatal con otro actor, el Estado de origen siempre mirará dicha relación con recelo, principalmente por la posible insurgencia de movimientos protodiplomáticos. Si esta relación es llevada a cabo con otros actores que no son gobiernos centrales, como en el caso de los kurdos, los Estados donde se ubiquen los actores de destino también tratarán de intervenir de un modo u otro, ya sea intentando acercarse -como Turquía con el GRK-o boicoteando la actividad -como el caso de Siria con éste último-.

A su vez, este recelo puede verse incrementado por la presencia de grupos separatistas y/o de colectivos terroristas, los cuales suelen ser frecuentes en este tipo de relaciones, tal como ocurrió en su época con el Frente de Liberación de Quebec y como sucede todavía con 
ETA y el PKK. En consecuencia, la existencia de estos grupos es un factor que dificulta cualquier acercamiento entre todos los actores involucrados.

También es importante señalar que mientras más sean los agentes que intervienen en el proceso, las posibilidades de institucionalizar estas vías alternas serán menores, tal como queda evidenciado con el caso de los kurdos, donde no solamente se involucran más de dos gobiernos centrales, sino que la poca autonomía de los agentes impulsa la proliferación de colectividades que buscan participar en este proceso, tales como los partidos políticos, contingentes paramilitares y demás gobiernos regionales.

Por su parte, las duraciones de los procesos entre los tres casos evidencian que, a mayor tiempo invertido en desarrollar la actividad paradiplomática se corresponde un mayor grado de institucionalización, el cual, a su vez, promueve los vínculos entre ambos actores. Así, la antigüedad demuestra ser un factor clave no sólo en el despliegue de mecanismos, sino en el perfeccionamiento de la estructura, tal como puede observarse al comparar el proceso de institucionalización de Quebec con el del GRK.

Por último, es importante subrayar la relevancia que juegan las ideologías, los sucesos de coyuntura y las cuestiones geopolíticas. En primer lugar, los antagonismos ideológicos -en términos políticosson de tal fuerza, que llegan a obstaculizar la cooperación entre dos colectividades que se sienten parte de una misma colectividad. En este sentido, los momentos de ruptura entre los vascos y los kurdos permiten ilustrar este punto. En segundo lugar, los periodos coyunturales son sumamente definitorios en cuanto a la dirección de la actividad paradiplomática, ya que permiten bloquearla o motorizarla. Lo anterior no pretende ser un llamado al carácter ideográfico, pero sí intenta otorgarle a este tipo de eventos el lugar tan importante que merecen. Por último, se desprende del análisis de los tres casos que el factor geopolítico continúa siendo un elemento clave para el entendimiento de las relaciones internacionales, tal como lo evidencia el caso del Kurdistán iraquí que, a diferencia de Quebec o la región 
vasca, no tienen la misma importancia en cuanto a recursos -petrolíferos- y su ubicación -en el centro del Medio Oriente y de los grandes oleoductos-.

\section{Conclusiones}

A pesar de la reciente inclusión de la paradiplomacia en los estudios de Relaciones Internacionales, ésta continúa cimentándose como uno de los grandes tópicos en dicha área. En este sentido, los análisis que se desprendan de la misma contarán con la ventaja de poder adaptar las teorías que se han desarrollado dentro de los estudios de los Estados-nación al caso de los gobiernos subnacionales, tal como ocurre con la inclusión de la variable identitaria.

Partiendo de dicha visión, el propósito de este artículo ha sido demostrar la importancia de compartir una identidad en la relación que genera un gobierno subnacional con otro agente exterior, resaltando de modo particular cómo influye la identificación en la elección de dicho actor. Asimismo, se ha intentado señalar la forma en que esta identidad compartida se ve materializada en la relación, tal como queda evidenciado en los discursos políticos, intercambios académicos para motivar el uso del idioma en común, circuitos transfronterizos que buscan promover una identidad y demás acuerdos de preservación cultural. En síntesis, la reflexión sobre las motivaciones y los fines de la actividad paradiplomática ha sido orientada a observar el modo en que la identidad impulsa las relaciones exteriores con ciertos actores e igualmente, a entender como ésta puede ser un objetivo en sí mismo dentro de dicha actividad.

Aunque dicho objetivo queda retratado en los tres casos de estudio, también es importante rescatar una serie de observaciones previas al cierre. En primer lugar cabe mencionar que, a pesar de los progresos realizados en el campo paradiplomático, el paradigma estatocentrista sigue teniendo un peso considerable incluso en las regiones que gozan jurídicamente de una autonomía. Así, el papel de los Estados y de los gobiernos centrales figura como un elemento imperdible en cualquier tipo de relación paradiplomática, ya sea identitaria o no. 
En este sentido, las reconfiguraciones actuales de los Estados no han terminado por limitar su papel en la arena internacional, de modo que en muchas ocasiones las relaciones entre gobiernos subnacionales se ven altamente influenciadas por los posicionamientos que adoptan los primeros.

En segundo lugar, si bien la variable identitaria es fundamental para construir un panorama interpretativo más integral, también es cierto que las variables tradicionales continúan posicionándose como elementos de alto valor explicativo. $\mathrm{Al}$ respecto, puede ocurrir que la compartición de una identidad no sea tan fuerte para potencializar la cooperación, como sí lo son los factores geopolíticos para minarla, de modo que en un caso como el kurdo, la identidad puede llegar a perder su centralidad dentro del análisis. Aún así, es importante considerarla dejando de lado una postura causal ante la realidad; en su lugar, ésta debe contemplarse a partir de una serie de variables que permiten constituirla, ya que un escenario tan complejo como el que se estudia no puede reducirse a un solo factor.

Por otra parte, el estudio de la paradiplomacia identitaria no debe limitarse a observarla únicamente como el producto de la diferenciación con respecto al Estado de origen, tal como se recoge en la obra de Paquin (2003; 2004). Al respecto, no sólo importa lo diferente que sea el actor en relación a la comunidad nacional, sino con cuál actor comparte atributos de modo que ambas partes se sientan tan identificadas que motiven este tipo de canales. Más aún, ello invita a repensar el estudio de la paradiplomacia identitaria en una relación tripartita, desplazando así los vínculos duales -hacia el gobierno central o hacia el actor de destino- con que ha sido tratada. Consecuentemente, esto contribuirá a enfatizar la distinción que se maneja frente a la protodiplomacia, ya que, como ha sido ilustrado, en numerosas ocasiones la identidad no es una finalidad en sí, sino que existe un objetivo mayor que la activa de modo que ésta, a su vez, impulsa los canales paradiplomáticos.

Así, del mismo modo que ocurre con los estudios de Relaciones Internacionales que se centran en los Estados, el campo de la paradiploma- 
cia no sólo se limita a la inclusión de variables racionalistas y utilitarias; por el contrario, las perspectivas para entender y explicar este fenómeno son tan amplias, que un cambio de enfoque o la inclusión de alguna variable producirán nuevos caminos para entender esta tendencia. En lo que a este artículo respecta, la identidad ha contribuido a mejorar la comprensión acerca de las motivaciones que tienen algunos gobiernos subnacionales al momento de planear y desarrollar sus relaciones con el exterior, principalmente cuando los lazos culturales son tan centrales que conforman el motor paradiplomático.

\section{Referencias}

Aldecoa, F, \& Keating, M. (1999). Paradiplomacy in Action: The Foreing Relations of Subnational Governments. Gran Bretaña: Psychology Press.

Arakelyan, A. (2013). Emerging Paradigms of Kurdish Nationhood in the Middle East (Tesis de Maestría, American University of Armenia, Yereván, Armenia).

Assir, S. (30 de agosto de 2014). Kurds put aside old rivalries to battle jihadists in Iraq. Recuperado de: http://www.middle-east-online.com/ english $/$ ?id $=67858$

Berenskoetter, F. (2014). Parameters of a national biography. European Journal of International Relations, 20(1), 262-288.

Bloom, W. (1993). Personal Identity, National Identity and International Relations. Gran Bretaña: Cambridge University Press.

Bozdağlioğlu, Y. (2003). Turkish foreign policy and Turkish identity: a constructivist approach. Gran Bretaña: Routledge Series.

Calonge Velázquez, A. (2013). El derecho de secesión en Canadá: una regulación jurídica completa y un problema político sin resolver. Revista de Derecho de la Unión Europea, 25, 107-124.

Changfoot, N., \& Cullen, B. (2011). Why is Quebec separatism off the agenda? Reducing national unity crisis in the neoliberal era. Canadian Journal of Political Science, 44(4), 769-787.

Charountaki, M. (2012). Turkish Foreign Policy and the Kurdistan Regional Government. Perceptions, 17(4), 185-208.

Consejo de desarrollo del País Vasco. (2003). Les coopération transfrontalières en Pays Basque. Recuperado de http://www.lurraldea.net/fr/bibliodocs/ entrees-transversales/cooperation-transfrontaliere.html 
Consulado General de Francia en Quebec. (2015). Histoire des relations bilatérales entre la France et le Québec. Recuperado de http:/ / www.consulfrancequebec.org/Histoire-des-relations-bilaterales

Cuenca Miranda, F. (2013). Canadá y la cuestión de Quebec (I): La separación-integración de Quebec en el federalismo canadiense. Cuadernos de Pensamiento Político, 39, 83-105.

Duchacek, I. (1990). Perforated Sovereignties: Towards a tipology of new actor in international relations. En H. Michelmann \& P. Soldatos (Eds.). Federalism and International Relations: The Role of Subnational Units, (pp.1-33). United Kingdom: Clarendon Press.

El-Dessouki, A. I. (2012). Structural Contexts and Paradiplomacy of Iraqi Kurdistan. Al-Nabda, 13(2), 1-38.

Emmerich, G. E. (2003). Apogeo y declinación del soberanismo quebequense. Polis: Investigación y Análisis Sociopolitico y Psicosocial, 3(2), 149-171.

Filibi, I. (2009). Integración europea y la apuesta vasca por la cooperación transfronteriza: el fondo propio Aquitania-Euskadi. En C. Cancela Outeda (Coord.), Cooperación Transfronteriza: comparando las experiencias ibéricas, (pp. 9-42). Santiago de Compostela: Tórculo Ediciones.

Finnemore, M., \& Sikkink, K. (1998). International Norm Dynamics and Political Change. International Organizations, 52(4), 887-917.

Gayon, B. (2011). Construction identitaire et coopération transfrontalière au Pays Basque. France: Tours.

Giddens, A. (1995). Modernidad e identidad del yo: el yo y la sociedad en la época contemporánea. Barcelona: Península.

Giménez, G. (2004). Materiales para una teoría de las identidades sociales. En J. M. Valenzuela Arce (Coord.), Decadencia y auge de las identidades: cultura nacional, identidad cultural y modernización. México: Plaza y Valdés, Colegio de la Frontera Norte.

Gobierno de Quebec. (2002). Québec-France Protait d'une relation en mouvement. Quebec: Ministerio de Relaciones Internacionales.

Gómez García, P. (2001). Las desilusiones de la identidad: la etnia como seudoconcepto En P. Gómez García (Ed.), Las ilusiones de la identidad. Madrid: Universitat de València.

Guillaume, X. (2011). International Relations and Identity: A dialogical approach. Nueva York: Routledge Series.

Hopf, T. (2002). Social Construction of International Politics: Identities and Foreign Policies. Estados Unidos: Cornell University Press. 
Katzenstein, P. (Coord.) (1996). The Culture of National Security: Norms and Identity in World Politics. Estados Unidos: Columbia University Press.

Keating, M. (1997). Les défis du nationalismes moderne: Québec, Catalogne, Écosse. Montreal: Les Presses de l'Université de Montréal.

Kelly, M. J. (2010). The Kurdish Regional Constitution within the Framework of the Iraqi Federal Constitution: A Struggle for Sovereignty, Oil, Ethnic Identity, and the Prospects for a Reverse Supremacy Clause. Penn State Law Review, 114(3), 707-808.

Keohane, R., \& Nye, J. (1987). Transnational Relations and World Politics. International Organization, 4(41), 725-753.

Kubálková, V. (Coord.). (2001). Foreign Policy in a Constructed World. Estados Unidos: M. E. Sharpe.

Laclau, E., (2011). La razón populista. Buenos Aires: Fondo de Cultura Económica.

Lapid, Y., \& Kratochwil, F. (eds.) (1996). The Return of Culture and Identity in IR Theory. Estados Unidos: Lynne Rienner Publishers.

Lecours, A. (2002). Paradiplomacy on the Foreign Policy and International Relations of Regions. International Negotiation (7), 91-114.

Legaré, A. (2005). La France et le Québec. Cités: 23, 89-104.

López Basaguren, A. (2014). Parti Québecois: ¿una reflexión post-mortem? Recuperado de: http://www.eldiario.es/agendapublica/reforma-constitucional/Parti-quebecois-reflexion-post-mortem_0_248475339.html

Lopez Vallejo, M. (2002). Federalismo y relaciones internacionales: comparación de la actividad internacional de unidades federadas en Canadá y Estados Unidos (Tesis de Maestría, Universidad de las Américas, Puebla, México).

Lundgren, A. (2007). The Unwelcome Neighbour: Turkish's Kurdish Policy. Gran Bretaña: I. B. Tauris.

Ministerio de Relaciones Internacionales y de la Francofonía. (2015). Coopération Déscentralisée. Recuperado de http://www.mrif.gouv.qc.ca/fr/ relations-du-quebec/europe/france/relations-politiques/cooperationdecentralisee

Mitzen, J. (2006). Ontological Security in World Politics: State Identity and the Security Dilemma. European Journal of International Relations, 12(3), 341-370.

Mohammed, H. K., \& Owtram, F. (2014). Paradiplomacy of Regional Governments in International Relations: The Foreign Relations of the 
Kurdistan Regional Government (2003-2010). Iran and the Caucasus, 18, 65-84.

Morin, J. Y. (2008). Les relations entre le Québec et la France. En G. Plourde, H. Duval \& P. Georgeault (coords.), Le français au Québec: 400 ans d'bistoire et de vie. Québec: Les Editions Fides.

Mouffe, C. (2011). En torno a lo político. Buenos Aires: Fondo de Cultura Económica.

Onuf, N. G. (2013). Making Sense, Making Worlds: Constructivism in social theory and international relations. Gran Bretaña: Routledge.

Ortega Ramírez, A. (2012). Los gobiernos locales como actores internacionales, reflexiones teóricas. Trabajos de Investigación en Paradiplomacia, 3(1), 17-38.

Paquin, S. (2003). Paradiplomatie identitaire en Catalogne. Canadá: Les presses de l'Université Laval.

Paquin, S. (2004). Paradiplomatie et relations internationales: Théorie des strategies internationales de régions face à la mondialisation. Alemania: P.I.E. Peter Lang.

Park, B. (2012). Turkey, the US and the KRG: Moving Parts and the Geopolitical Realities. Insight Turkey, 14(3), 109-125.

Ponce, E. A. (2011). Historia y actualidad de la acción exterior de los gobiernos locales. Trabajos de Investigación en Paradiplomacia, 1(1), 12-43.

Ruiz Robledo, A. (1993). El federalismo canadiense. Cuadernos de la Cátedra Fadrique Furió Ceriol, 2, 47-56.

Sarquís, D. J. (2013). Fundamentos teóricos para la reflexión en torno a la paradiplomacia. En Z. Zeraoui (Coord.). Teoría y práctica de la paradiplomacia, (pp. 45-92). México: Montiel y Soriano.

Steele, B. J. (2008). Ontological security in International Relations: self identity and IR state. Nueva York: Routledge.

Subotic, J., \& Zarakol, A. (2013). Cultural intimacy in International Relations. European Journal of International Relations, 19(4), 915-938.

Synovitz, R. (26 de noviembre de 2014). Putting Rivalries Aside, AllMain Kurdish Parties To Meet For First Time. Recuperado de: http:/ /www.rferl.org/ content/iran-iraq-kurdish-parties-conference-irbil/25080726.html

Thériault, J. Y. (2008). La langue, symbole de l'identité québécoise. En G. Plourde, H. Duval \& P. Georgeault (Coords.) Le français au Québec: 400 ans d'histoire et de vie, (pp. 318-324). Québec: Les Editions Fides.

Thérien, J. P. Bélanger, L., \& Gosselin, G. (1996). El surgimiento de un nuevo actor internacional. En P. Martín, A. Noël \& B. J. R. Stevenson 
(Coords.), Interpretaciones de la Quebec contemporánea, (pp. 217-242). México: Porrúa.

Velázquez, R. (2006). La paradiplomacia mexicana: las relaciones exteriores de las entidades federativas. Relaciones Internacionales, 96, 123-149.

Villellas, A. (2014). The Kurds in the spotlight: local and regional challenges. Recuperado de: http://www.peacebuilding.no/var/ezflow_site/storage/ original/application/d4b84c60bf5f115c7af37456844190d6.pdf

Wendt, A. (1996). Identity and Structural Change in International Politics. En Y. Lapid \& F. Kratochwil (Eds.), The Return of Culture and Identity in IR Theory, (pp. 47-64). Estados Unidos: Lynne Rienner Publishers.

Wendt, A. (1999). Social Theory of International Politics. Reino Unido: Cambridge University Press.

Zeraoui, Z. (2013). La paradiplomacia y las relaciones internacionales de las regiones. En Zeraoui, Z. (Coord.). Teoría y práctica de la paradiplomacia, (pp. 9-43). México: Montiel y Soriano.

Zulal, S. (2012). Survival Strategies and Diplomatic Tools: The Kurdistan Region's Foreign Policy Outlook. Insight Turkey, 14(3), 141-158. 